\title{
Programa mais educação: responsabilização e comprometimento coletivo para um desenvolvimento humano e sustentável
}

\section{Mais educação (increased education) program: responsibilization and collective commitment for human and sustainable development}

\author{
Maria Deuceny da Silva Lopes Bravo Pinheiro*, Alfredo Bravo Marques Pinheiro**, António Gomes Ferreira** \\ * Rede Municipal de Ensino de Cachoeiro de Itapemirim,;** Universidade de Coimbra;
}

\begin{abstract}
Resumo
Esta comunicação apresenta um recorte da análise feita sobre o desenvolvimento do Programa Mais Educação em Cachoeiro de Itapemirim, ES, Brasil. O Programa, pautado nos baixos índices de aprendizagem das escolas públicas brasileiras, apresenta uma concepção holística de educação voltada para uma formação plena do cidadão e para o desenvolvimento sustentável. Conduzimos nosso estudo enfatizando a importância da participação como dispositivo de responsabilização e comprometimento coletivo. Os dados apresentados enfatizam o quão significativos podem ser os arranjos educativos envolvendo escola, família e comunidade para o desenvolvimento de uma cultura de cidadania e de transformação social.

Palavras-chave: Educação Integral, Programa Mais Educação, Desenvolvimento Sustentado
\end{abstract}

\begin{abstract}
This communication presents a cut of the analysis made on the development of the More Education Program in Cachoeiro de Itapemirim, ES, Brazil. The program, based on the low rates of learning of Brazilian public schools, presents a holistic conception of education geared towards full citizen training and sustainable development. In this sense, we conducted our study emphasizing the importance of participation as a device of accountability and collective commitment. The data presented emphasize how significant the educational arrangements involving school, family and community can be for the development of a culture of citizenship and social transformation
\end{abstract}

\section{Introdução}

A contemporaneidade tem se caracterizado pelas indagações acerca de caminhos para um mundo mais sustentável, provocando reflexões e questionamentos sobre o papel da escola na formação dos cidadãos e as concepções que essa instituição formal tem sobre os tempos e espaços de aprendizagem. Nesse sentido, a presente comunicação ao apresentar um recorte da análise feita sobre o Programa Mais Educação, propõe uma reflexão sobre a importância da abertura da escola aos contextos locais através do compartilhamento da responsabilidade educativa entre família, escola e poder público de forma a trabalhar o território como ambiente privilegiado para o exercício pleno da democracia, para a participação cidadã e para um desenvolvimento mais sustentado.

$\mathrm{O}$ estudo fundamenta-se nos princípios norteadores das Cidades Educadoras (AICE, 2004) para trabalhar a premissa da cidade como um espaço democrático e inclusivo a ser usufruído equitativamente por todos aqueles que nela habitam e vivem o seu cotidiano. Assim, ao falarmos de desenvolvimento integral, pensamos na plenitude do cidadão que deve constituir o âmago desse processo.

Os dados apresentados resultam de um estudo de caso desenvolvido nas seis escolas que iniciaram o Programa Mais Educação no município de Cachoeiro de Itapemirim, ES, Brasil. Os resultados apontam que o Programa Mais Educação, apesar da concepção assistencialista predominante, assinalou avanços na promoção da cidadania, evidenciados nas mudanças de comportamento dos estudantes. Embora o investimento nos aspectos socioemocionais seja significativo, para que o Programa alcance sucesso é preciso que ele volte sua atenção para a questão da aprendizagem também. Nesse sentido, o desenvolvimento de um projeto educativo local envolvendo escola, família e comunidade, voltado para as componentes cognitivas e socioemocionais, tendem a garantir o sucesso escolar e o desenvolvimento humano sustentado.

\section{Educar na cidade}

A cidade, historicamente, tem se revelado um espaço aglutinador de diferentes grupos humanos, num processo de interação permanente com o território, seja marcada por uma infraestrutura física, criada para o abastecimento e o desenvolvimento de suas diversas atividades, seja por abrigar práticas sociais que vão transformando a imagem desse espaço em conformidade com o uso que os indivíduos fazem dele. Local de troca, espaço de aprendizagem e convivência, as diferentes representações de cidade e as diversas concepções resultantes da experiência pessoal fazem dela um espaço plural e diversificado, com uma 
socialização de normas morais e culturais, resultantes de uma herança cultural, social, tecnológica, acadêmica e funcional que envolve um sistema formado por diferentes instituições e espaços educativos (Alderoqui, 2006). Nesse sentido, a cidade revela potencial pedagógico que decorre da compreensão do que tem sido e do que venha ser, da consciência da sua configuração e das relações e produções que encerra. Assim, aprende-se com a cidade quando se interpreta seu espaço como categoria geográfica, social, política, cultural e histórica, graças ao leque de ofertas e situações educativas que combinam recursos humanos e materiais existentes nesse território.

Equilibrando diferentes funções entre o público e o privado, a cidade é um convite para um olhar mais pedagógico sobre seu território, um olhar que possibilite ver além da aparência (Arendt, 2007), sair do individualismo para uma vivência mais coletiva que colabore para construção de cidadãos mais persuasivos e democráticos, num mundo cada vez mais globalizado. Daí, a necessidade de se re/inventar o território coletivo (Hansotte, 2005) e resgatar os espaços públicos proporcionando ao cidadão uma participação mais ativa, responsável e transformadora sobre o território.

Se os gregos foram capazes de criar a democracia a partir do momento que descobriram que a ordem social não era ditada pelos deuses, mas construída pelos homens, vislumbrando com isso a possibilidade de construir uma sociedade cujo destino não estivesse fora dela, mas nas mãos de todos que dela participavam (Toro \& Werneck, 1996), também nós somos capazes de imaginar formas e configurações urbanas que incorporem os novos avanços tecnológicos e permitam a sua legibilidade, re/conquista e recuperação de sua função coletiva, nomeadamente por ela estar relacionada aos diferentes modos de vida que aglutina.

É possível explorar pedagogicamente a cidade quando se estabelece uma relação estreita dos seus cidadãos para com ela (Tuan, 1983), quando os diferentes agentes e instituições existentes no território subsidiam a concepção da cidade como espaço educativo, construindo e re/descobrindo espaços (Almeida, 2008; Alferi, 2009; Villar, 2007), quando os poderes buscam uma interação responsável das pessoas com o patrimônio, quando estas interagem com o que as rodeia, tendo em vista aprender a compreender-se e a renovar a sociedade perante as novas condições e necessidades.

As diferentes lentes que observam a cidade podem revelar cenas inéditas e detalhes de um cotidiano diversificado, numa compreensão para além da aparência observada, com um conhecimento sobre como fazer uso desse espaço e promover sua sustentabilidade. Como é evidente, tudo isso pressupõe uma concepção de educação mais ampla do que a que é normalmente veiculada e demasiada focada na escola. Nesse cenário, um olhar diferenciado e interdisciplinar sobre a cidade desvela o potencial educativo existente nesse espaço, com suas instituições, agentes, equipamentos, revelando o quanto a educação pode contribuir para a sua compreensão e apreensão. Para isso, há que se explorar novas fórmulas pedagógicas que assegurem maior oferta de oportunidades educativas e possam preparar as pessoas para sociedades mais participativas e, consequentemente, mais democráticas.

\section{Responsabiliz(Ação) e comprometimento coletivo}

O sentimento de pertença sempre foi o elemento central na concepção do território, fortalecendo vínculos, interagindo serviços, criando identidades, constituindo-se base do trabalho por aqueles que habitam, constroem e usufruem dos recursos materiais, espirituais e culturais, naturais e artificiais que o espaço oferece (Tuan, 1983). Na modernidade, o espaço dominado e/ou apropriado do passado deu lugar a uma multiplicidade de novos territórios interligados pela tecnologia, pela mobilidade internacional e multicultural bem diversificada. Novas escalas locais, regionais e globais vão sendo construídas e desconstruídas, reforçando a necessidade de se estreitar o laço de pertencimento com o território e assim, garantir sua sustentabilidade (Alderoqui, 2003; Santos, 2011). Esta é a importância de uma relação estreita do cidadão com o território, de se investir no espaço público para que ele possa se tornar um espaço de usufruto coletivo e de aprendizagem e, como a pólis, apresentar-se, também, como espaço de discussão de assuntos ligados à vida da cidade e aos interesses das comunidades que a compõem. Torna-se, assim, necessário repensar o espaço público, pois muitos dos que assim são juridicamente, tem sido usados por pessoas, grupos, entidades como coisa sua, prejudicando eventuais dinâmicas sociais e culturais, capazes de aumentar as ocasiões de aprendizagem e desenvolvimento da cidadania.

A cidadania, na modernidade, engloba uma palavrachave fundamental para seu processo de desenvolvimento e promoção social, que é a participação, através do sentimento comunitário e colaborativo de uma comunidade específica (Cardona, 2006). Nesse sentido, a construção de uma cidadania global implica em mudanças de posturas, participação ativa e iniciativa para assumir compromissos diante dos problemas vivenciados, com vistas à construção de um mundo mais justo e solidário. Daí, a importância do compartilhamento de saberes, de vivências e experiências integrando conhecimentos formais com a cultura local, sustentando o diálogo e a parceria entre a escola e a comunidade, numa sensibilização motivadora à participação e mobilização de recursos e equipamentos que colaborem na construção de um território educativo. As possibilidades do exercício da cidadania permitem ver o grau de democraticidade e de coesão da sociedade. A definição da cidadania numa cidade diz-nos o quanto esta é mais ou menos hierarquizada, mais ou menos democrática, mais ou menos aberta. Assim, mais que o direito político do indivíduo, a cidadania engloba o exercício sobre o espaço público no interesse do bem comum.

Essa nova cultura de cidade, de educação e de gestão pública, incide sobre o amplo leque de iniciativas educadoras que ocorrem no território e podem ser 
incentivadas através da cooperação e construção de novas relações sociais, que aproximem e aumentem a relação de pertencimento e comprometimento do cidadão com o território (Villar, 2007). As parcerias com iniciativas de diversos segmentos governamentais e não governamentais propiciam ampliar o leque de oferta de oportunidades, de formação e participação coletiva do cidadão, tanto em qualidade quanto em quantidade, habilitando-os com suficiente formação e informação, na construção do bem-estar comum.

Essa nova lente, esse novo olhar que se volta para a cidade possibilita o conhecimento, a interpretação e a compreensão dos diversos códigos e símbolos existentes na linguagem dos habitantes e na forma como os espaços vão sendo ocupados (Hansotte, 2005) e contribui para a formação de um cidadão ativo, pois além de um direito à cidade, revela também o dever dos cidadãos para com ela.

\section{Educando para a sustentabilidade}

Como é evidente, tudo isso pressupõe uma concepção de educação mais ampla do que a que é normalmente veiculada e demasiada focada na escola. Há que explorar novas fórmulas pedagógicas que assegurem maior oferta de oportunidades educativas e possam preparar as pessoas para sociedades mais participativas e, consequentemente, mais democráticas, o que deve assentar no reconhecimento e na valorização do papel da cidade na construção da identidade individual, comunitária e coletiva (Nóvoa, 2009; Gadotti, 2005; Villar, 2007). O desafio de ressignificar o espaço escolar e o processo educativo, para além dos limites da sala de aula e dos métodos tradicionais de ensino para considerá-los em sua totalidade, envolve o reconhecimento da diversidade cultural presente em seu contexto. Envolve, ainda, uma ruptura da configuração segmentada e do direcionamento individual predominante que ainda se faz presente na escola, que possibilite a interação do indivíduo com o território, na produção de um conhecimento relevante para si e para o mundo, na promoção de uma educação integral.

Na prática, as políticas públicas de educação integral no Brasil têm se caracterizado por propostas que abarcam diferentes tempos, espaços e agentes educativos e avançam timidamente para o território, com vistas a permitir aos estudantes acesso a diferentes contextos que possibilitem o desenvolvimento de suas capacidades físicas, sociais, afetivas e intelectuais. Alargando esse conceito, entendemos que a educação integral deve conceber-se também ao longo da vida, considerando diferentes idades, diferentes escalas e contextos, diversos formatos e técnicas, de modo a corresponder a interesses múltiplos e diversificados, com vistas à atualização da formação das pessoas ou à satisfação da sua curiosidade intelectual e desejo de saber ou fazer, contribuindo para a transformação do mundo em que vivemos.

Quando o Programa Mais Educação foi criado no Brasil, no ano de 2007, para contribuir na melhoria dos índices de aprendizagem das escolas públicas brasileiras, ele surgiu com uma proposta de organização curricular na perspectiva da educação integral. Propondo uma metodologia participativa, entre as políticas públicas educacionais e sociais, através de parcerias e ampliação de tempos e espaços educativos que envolvesse a participação da família e da comunidade na construção de uma agenda intersetorial (Brasil, 2013), a oferta de redes educativas teve o intuito de contribuir para o Desenvolvimento Humano e Sustentável. A proposta apresentada e desenvolvida nos macrocampos, com as diversas oficinas ofertadas era explorar as vivências, sensibilizando para a intencionalidade educativa da cidade.

Nesse sentido, os macrocampos iniciaram um processo educativo mais democrático de aproximação da escola com a comunidade, provocada pela necessidade de parcerias para o desenvolvimento das atividades. Além de mudarem a rotina da escola e da comunidade escolar, registramos, no discurso em nosso estudo, que a maior potencialidade do Programa Mais Educação foi a mudança de comportamento e de atitudes dos estudantes envolvidos, o que reforça a relevância da promoção de atividades de impacto socioemocial para o desenvolvimento integral e sustentado.

A educação se apresenta como uma componente essencial para o aumento sustentado. $\mathrm{O}$ entendimento de desenvolvimento sustentável comporta a ideia de território e a contribuição dos cidadãos para um desenvolvimento global e harmonioso. Nesse sentido, pensamos em uma educação capaz de propiciar e desenvolver a consciência de que não estamos sozinhos, que fazemos parte de um cosmo e que o desenvolvimento humano é premissa para a construção de uma sociedade mais democrática, justa, equitativa e, consequentemente, onde a sustentabilidade representa a meta norteadora de um progresso menos materialista. É ela que possibilita a articulação do conhecimento, não como um fim em si mesmo, mas como estratégia para ampliação do conhecimento e da intervenção crítica consciente. A educação deve, portanto, contemplar dispositivos que visem a aprendizagens que amplifiquem o conhecimento do mundo, das sociedades, da ciência, das culturas, das pessoas. Importa que a informação tenha sentido para a generalidade da população, que esta possa usá-la e beneficiar-se dela.

A necessidade de aprendizagem sustentada exige atenção sobre o modo como se ensina e requer colaboração, engajamento da comunidade, de atores sociais e segmentos produtivos, num esforço conjunto voltado para a educação ao longo da vida. Só uma política educativa que tenha esta preocupação com a atualização do conhecimento e com a motivação para a aprendizagem poderá servir à construção de um território mais equilibrado, de uma sociedade mais coesa, de uma democracia mais dinâmica.

Não há dúvidas que o Programa Mais Educação fomentou a Educação Integral no Brasil. Com diretrizes norteadoras, colaborou para que os Estados e os Municípios, a partir de suas respectivas realidades, desenvolvessem diferentes experiências e arranjos para 
a oferta de Educação Integral no país (Itaú Social \& Banco Mundial/MEC, 2015). As atividades extracurriculares, quando inseridas no currículo escolar, apresentam-se como alternativa para minimizar as desigualdades sociais e garantir a qualidade do ensino. No entanto, apesar de sua abrangência, o Programa registrou vários desafios, vinculados, em grande parte, à diversidade do território brasileiro e, consequentemente, às adequações ao contexto dos Estados e Municípios, principalmente no que se refere ao financiamento, pois além do repasse do governo federal, o Programa ficou subjacente ao assessoramento e à articulação da rede pública à qual pertence suas escolas.

O Programa Mais Educação é considerado um avanço na política pública educacional brasileira, alinhando-se às reformas educacionais que vêm sendo desenvolvidas na América Latina (Itaú Social e Banco Mundial/MEC, 2015). Em cada uma das escolas investigadas, em nosso estudo, os atores entrevistados revelaram que perceberam o desenvolvimento social dos alunos, que houve melhoria na socialização, no relacionamento professor-aluno e que houve registro de mudanças na vida desses estudantes. Isso sinaliza que o ensino, quando envolve uma ação humanizante, contribui para uma ação transformadora, permitindo que o estudante exerça sua cidadania, notadamente porque ele aprende a se colocar no lugar do outro, respeitar as diferenças e viver coletivamente.

As políticas públicas têm direcionado suas ações pautadas na mensuração dos resultados, o que justifica o Programa ter preocupação com o rendimento escolar, principalmente porque, em primeira análise, os resultados alcançados no IDEB não foram os desejados. Porém, não podemos deixar de mencionar os contributos significativos que o tempo de permanência do estudante na escola e as atividades socioculturais desenvolvidas tiveram na melhoria no comportamento, na convivência coletiva e na mudança de hábitos e atitudes dos estudantes. Sem dúvida, esses elementos favorecem a aprendizagem e contribuem para a convivência na sociedade e para $o$ desenvolvimento da cidadania. O ideal é que uma política desse gênero se mantenha a trabalhar com um conjunto de comportamentos e atitudes sem desconsiderar a componente cognitiva.

A educação só faz sentido porque há um coletivo humano. A educação existe porque se reconhece pertinência à passagem de conhecimento, nomeadamente o que é legado pela geração anterior. Mas também existe porque deverá proporcionar uma formação capaz de assegurar um futuro melhor a uma sociedade. Independentemente da compreensão de Educação de Tempo Integral no Brasil fazer todo sentido em face do esforço para implementar a escola a tempo inteiro, devemos recuperar o sentido primordial de Educação Integral. Embora o investimento nos aspectos socioemocionais seja significativo, para que o Programa alcance sucesso é preciso que ele volte sua atenção para a questão da aprendizagem também. Para desenvolver esse conjunto de competências, é necessário trabalhar tanto no âmbito de políticas públicas educacionais, quanto no uso de práticas pedagógicas que possibilitem estruturar e explicitar essas políticas durante o processo de aprendizagem em sala de aula. Só uma política educativa que tenha esta preocupação com a atualização do conhecimento e com a motivação para a aprendizagem poderá servir à construção de um território mais equilibrado, de uma sociedade mais coesa, de uma democracia mais dinâmica.

Nesse sentido, considerando que a aprendizagem não acontece de maneira isolada, devemos considerar a dinamicidade da natureza humana e sua densidade antropológica para despertar no indivíduo a vocação humana para a transcendência, que fortaleça os sentimentos de pertença, estreite os laços sociais e desenvolva valores, comportamentos e atitudes de vinculação ética, de respeito e de sensibilidade que fomentem práticas sociais, econômicas e políticas de sustentabilidade.

Pensamos que só pode haver uma política educativa consistente se for adequada às exigências civilizacionais do tempo, se as pessoas se sentirem interessadas, forem ativas, buscarem aprender constantemente, souberem relacionar-se com os outros, se a sociedade tender a transformar-se por via de uma educação mais democrática, mais atenta às particularidades das culturas e à inovação, se encarar a necessidade de se buscar o sucesso de todos, garantindo condições para se evitar situações de desigualdade no acesso à informação e à cultura.

\section{Considerações finais}

As transformações que vivenciamos neste mundo global têm sido marcadas por uma crise das instituições, das estruturas e dos valores éticos e morais. Acreditamos na educação como força motriz capaz de fornecer elementos para que façamos escolhas seguras e sustentadas, tanto para viver o presente, como para prever e prover o futuro. A ampliação do conhecimento do mundo, das sociedades, das culturas e das pessoas, contribui para uma intervenção crítica e consciente inerente a um desenvolvimento humano sustentado. Isso envolve mudança de postura, de estilo de vida, de atitudes éticas e responsáveis com a qualidade de vida da geração atual e futura.

Embora o Programa Mais Educação tenha sido criado apregoando uma oferta mais democrática e equitativa de educação, com vistas a promover o desenvolvimento integral do estudante, apesar de ter um alto nível de consistência, relativamente aos seus princípios norteadores e à sua estrutura, a sua concepção precisa ainda ser apropriada pelos responsáveis por sua implementação e execução, nas dinâmicas de articulação da política local.

A necessidade de aprendizagem sustentada exige atenção sobre o modo como se ensina e requer colaboração e engajamento da comunidade, de atores

sociais e demais segmentos produtivos, num esforço conjunto voltado para a educação ao longo da vida. Só uma política educativa que tenha esta preocupação com a atualização do conhecimento e com a motivação para 
a aprendizagem poderá servir à construção de um território mais equilibrado, de uma sociedade mais coesa, de uma democracia mais dinâmica.

Sendo a escola ainda central na política educativa, ela deve abrir-se ao território e interagir com as forças vivas da cidade. Por sua vez, os diferentes agentes que tanto podem lucrar com a educação dos cidadãos precisam articular-se para que a comunidade possa beneficiar-se dos contributos de todos os que forem sentindo a necessidade de aprenderem.

No tempo em que estamos, precisamos ter clareza entre o que se pretende da escola e da comunidade, entre o que devemos esperar das famílias e como a escola deve relacionar-se com elas. De qualquer modo, temos de procurar o envolvimento da família na implementação do Programa Mais Educação, pois, além de englobar as vivências dos alunos, ela integra saberes que têm de ser considerados no diálogo com a escola, possibilitando uma atuação mais convergente e sistêmica. A família, a escola e a comunidade devem ter funções diferentes, mas ser pensadas em conjunto. Nenhum desses espaços, por si só, será capaz de proporcionar uma educação integral e uma educação pensada como reconstrução de aprendizagens, numa procura do conhecimento reconhecido pelo coletivo e apostado no bem comum.

\section{Referências}

Alderoqui, S. (2003). La ciudad: Un territorio que educa.Caderno CRH, Salvador (38) 153176, jan./jun. Disponível em http://www.cadernocrh.ufba.br/viewarticle.php?id=1 47

Associação Internacional de Cidades Educadoras (2004). Carta das Cidades Educadoras. Génova, nov. Disponível em http://w10.bcn.es/APPS/eduportal/pubFitxerAc.do?id doc $=84472$.

Brasil (2013). Manual Operacional de Educação Integral. Brasília/DF. Ministério da Educação Secretaria de Educação Básica. Diretoria de Currículos e Educação Integral.

Cardona, R. M. (2006). Ciudad, educación y escuela relaciones y acciones en la ciudad educadora.http://www.ungs.edu.ar/cm/uploaded_files /file/foro_educ/MONCADA EDUCACION-ESCUELA.pdf

Gadotti, M. (2005). A escola na cidade que educa. Cadernos Cenpec. 1, 133-139. Disponível emcadernos.cenpec.org.br/cadernos/index.php/cader nos/article/.../189

Hansotte, M. (2005). As inteligências cidadãs: como se adquire e inventa a palavra coletiva. Lisboa: Instituto Piaget.

MEC (2015). Relatório de Avaliação Econômica e Estudos Qualitativos: O Programa Mais Educação. São Paulo - SP: Fundação Itaú Social. Disponível em: http://www.redeitausocialdeavaliacao.org.br/wpcontent/uploads/2015/11/relat_Mais_Educa\%C3\%A 7\%C3\%A3o_COMPLETO_20151118.pdf
Nóvoa, A. (2009) Para uma formação de professores construída dentro da profissão. Disponível em http://www.revistaeducacion.educacion.es/re350/re3 50_09por.pdf

Santos, M. (2011). O espaço da cidadania e outras reflexões. Porto Alegre: Fundação Ulysses Guimarães (Coleção O Pensamento Político Brasileiro; v.3.

Toro, J. B. e Werneck, M. N. D. (1996). Mobilização social: um modo de construir a democracia e a participação. Unicef, Brasil

Tuan, Yi-Fu (1983). Espaço e lugar. São Paulo: Diefel S. A.

Villar, M. B. C. (2007). A cidade educadora: nova perspectiva de organização e intervenção municipal. (2.ed.), Lisboa: Instituto Piaget. 